Article

\title{
Optimization of the Energy Consumption of a Carbon Capture and Sequestration Related Carbon Dioxide Compression Processes
}

\author{
Steven Jackson * ${ }^{\mathbb{D}}$ and Eivind Brodal \\ Instituttet for ingeniørvitenskap og sikkerhet IVT, UiT Norges Arktiske Universitet, 9019 Tromsø, Norway; \\ eivind.brodal@uit.no \\ * Correspondence: steve.jackson@uit.no
}

Received: 26 March 2019; Accepted: 25 April 2019; Published: 26 April 2019

\begin{abstract}
It is likely that the future availability of energy from fossil fuels, such as natural gas, will be influenced by how efficiently the associated $\mathrm{CO}_{2}$ emissions can be mitigated using carbon capture and sequestration (CCS). In turn, understanding how CCS affects the efficient recovery of energy from fossil fuel reserves in different parts of the world requires data on how the performance of each part of a particular CCS scheme is affected by both technology specific parameters and location specific parameters, such as ambient temperature. This paper presents a study into how the energy consumption of an important element of all CCS schemes, the $\mathrm{CO}_{2}$ compression process, varies with compressor design, $\mathrm{CO}_{2}$ pipeline pressure, and cooling temperature. Post-combustion, pre-combustion, and oxyfuel capture scenarios are each considered. A range of optimization algorithms are used to ensure a consistent approach to optimization. The results show that energy consumption is minimized by compressor designs with multiple impellers per stage and carefully optimized stage pressure ratios. The results also form a performance map illustrating the energy consumption for $\mathrm{CO}_{2}$ compression processes that can be used in further study work and, in particular, CCS system models developed to study performance variation with ambient temperature.
\end{abstract}

Keywords: $\mathrm{CO}_{2}$; Compression; Optimization; CCS

\section{Introduction}

Carbon capture and sequestration (CCS) is recognized as an important strategy for reducing $\mathrm{CO}_{2}$ emissions, but its wide spread adoption is held-back by uncertainty over the energy consumption and cost impact implied by the additional infrastructure required because of this, the optimization of CCS processes to reduce their energy and cost impacts represents an important field of study.

The capture element of most CCS schemes is generally accepted to have the greatest impact on energy efficiency and cost. Lucquiaud et al. [1] report that for an "nth of a kind CCS plant with current state-of-the-art solvent technology" the energy needed by the capture plant will be 250-300 kWh of electrical energy per tonne $\mathrm{CO}_{2}$ captured $\left(\mathrm{kWh}_{\mathrm{e}} / \mathrm{tCO}_{2}\right)$, whereas estimates of the energy consumption for $\mathrm{CO}_{2}$ compression lie typically in the range $80-120 \mathrm{kWh} / \mathrm{tCO}$ [2]. $\mathrm{CO}_{2}$ compression is also a mature technology, with conventional multi-stage centrifugal $\mathrm{CO}_{2}$ compressor designs widely used in the fertilizer and petroleum industries [3]. Suppliers of large-capacity multi-stage centrifugal $\mathrm{CO}_{2}$ compressors include Dresser-Rand, General Electric (GE), and MAN Turbo and Diesel (MAN). Common industrial applications include enhanced oil recovery (EOR), fertilizer production, and CCS. MAN, for example, has operating references including an 8-stage compressor used for EOR with a discharge pressure of 187 bara and a capacity of $36 \mathrm{~kg} / \mathrm{s}$; a 10-stage compressor used in fertilized production with a discharge pressure of 200 bara and a capacity of $13 \mathrm{~kg} / \mathrm{s}$; and offers designs for 
capacities of up to $110 \mathrm{~kg} / \mathrm{h}$ [4]. Given that a $600 \mathrm{MW}$ natural gas combined cycle power plant with $90 \% \mathrm{CO}_{2}$ capture requires a $\mathrm{CO}_{2}$ compression capacity of approximately $56 \mathrm{~kg} / \mathrm{h} \mathrm{[5]}$, the scale-up of current industrial designs to CCS applications is generally considered unproblematic. As a result, fewer studies have been made into the optimization of the $\mathrm{CO}_{2}$ compression process than have been made for the capture processes.

Some studies have studied the optimization of $\mathrm{CO}_{2}$ compression in the context of a particular CCS capture technology. Romeo et al. [6] and Luo et al. [7] studied the optimum design for $\mathrm{CO}_{2}$ compression in the context of heat recovery into a steam cycle. Posch et al. [8] and Font-Palma et al. [9] studied the optimization of the oxyfuel flue gas purification process where the early parts of the $\mathrm{CO}_{2}$ compression process are integrated with the $\mathrm{CO}_{2}$ separation process. Other studies have looked at optimization from the perspective of comparing conventional compression approaches to newer unconventional approaches. Alabdulkarem et al. [10] studied the potential benefit of liquefaction and pumping. Harkina et al. [11] and Luo et al. [7] studied the benefits of using shockwave type compression. Pei et al. [12] studied the benefits of heat recovery using ORC. A small number of studies such as Calado [13] and Jackson et al. [14] have considered the optimum number of $\mathrm{CO}_{2}$ compression stages, but these have had a limited focus and do not apply their conclusions to the full set of operating parameters that could be expected in a range of typical CCS scenarios. Overall, most $\mathrm{CO}_{2}$ compressor optimization studies are limited to one specific CCS scenario and focus on the capture process rather than the compression process in itself. Many do not optimize stage pressure ratios or the number of compression stages. None have been identified that consider optimization of compressor design for a wide set of operating cases.

The aim of this study is to generate a set of $\mathrm{CO}_{2}$ compressor performance data that is based on the optimum number of compressor stages and stage pressure ratios for a wide range of operating cases. The specific intention is that this data can be used to support the development of a system model capable of comparing energy consumption of a wide variety of CCS scenarios.

\section{Method}

The compressor model used in this study was developed in MATLAB (2018a, The MathWorks, Natick, MA, United States) utilizing properties predictions from the TREND package (Thermodynamic Reference and Engineering Data 3.0., Lehrstuhl für Thermodynamik, Ruhr-Universität Bochum, Bochum, Germany). A literature review was conducted to identify a set of realistic $\mathrm{CO}_{2}$ compressor design parameters; the operating parameters for the three principle $\mathrm{CO}_{2}$ capture alternatives: Post-combustion, pre-combustion and oxyfuel; and the appropriate range of cooling temperatures and discharge pressures to be studied. Optimization of the compressor model for each set of parameters was carried out using algorithms available in MATLAB. Each of these elements of the study method are set out in Nomenclature.

\subsection{Compressor Modeling}

Conventional $\mathrm{CO}_{2}$ compressor designs can either be integrally geared type, with one impeller and one gas cooler per stage; or barrel type, with multiple impellers and one gas cooler per stage [3]. In both designs the pressure ratio per impeller is limited to around 2 for $\mathrm{CO}_{2}$ service and because of this, it is common to model $\mathrm{CO}_{2}$ compressors with a pressure ratio per stage limit, $\mathrm{Pr}<2$ [6]. In this study, the cases following this convention are called the constrained cases. In a barrel type compressor design it is common to use several impellers per stage, and with an integrally geared design this is also possible, although less common. When multiple impellers are used per stage, $\operatorname{Pr}$ can be greater than 2, and in some studies, unconventional compressor designs with a $\operatorname{Pr}$ of up to 10 have been investigated [7,11], although these compressor designs are still under development. In this study, all cases where $\operatorname{Pr}>2$ are referred to as unconstrained cases.

Figures 1 and 2 provides an illustration of a $\mathrm{CO}_{2}$ compressor design with $n$ stages, where $\operatorname{Pin}_{1}$ is the compressor feed pressure and Pout $t_{n}$ is the compressor discharge pressure. Each stage is assigned 
a sequential number, $i=\{1, \ldots, n\}$. $\operatorname{Pin}_{i}$ is the inlet pressure for stage $i$; $\operatorname{Pr}_{i}$ is the pressure ratio for stage $i$; and Pout $_{i}$ is the outlet pressure for stage $i$. The gas cooler pressure drop, $\Delta P$, and the gas cooler outlet temperature, To, are both equal for all stages. In all cases, $\Delta P$ is fixed at 0.5 bar and To is studied over a range.

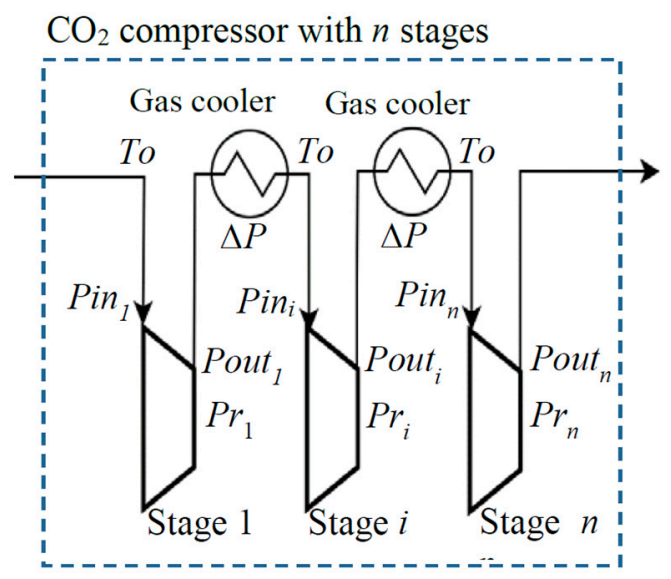

Figure 1. Illustration of a $\mathrm{CO}_{2}$ compressor design with $n$ stages.

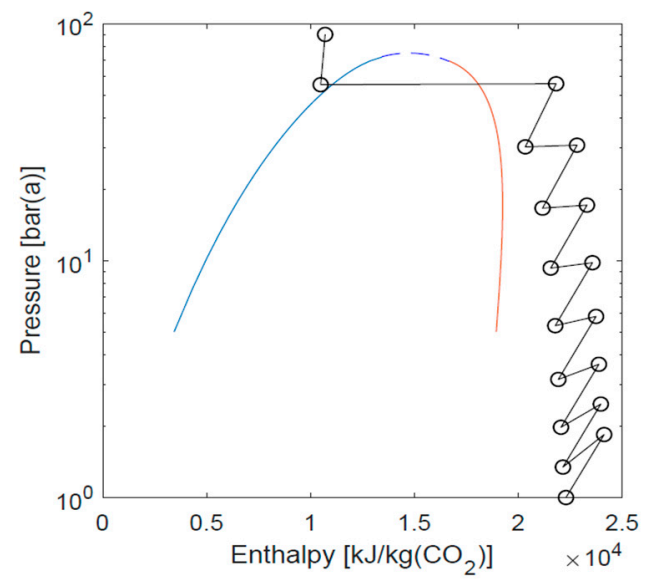

Figure 2. Illustration of a conventional nine-stage compressor in a pressure-enthalpy diagram.

The objective of the optimization study was to minimize the energy consumption required for compression, $W_{c}$, which was calculated in the model as follows:

$$
W_{c}=\sum_{i=1}^{n} \frac{\text { HoutS }_{i}-\text { Hin }_{i}}{\eta},
$$

where $\mathrm{HoutS}_{i}$ is the enthalpy at the outlet of an isentropic compression stage; Hin $n_{i}$ is the enthalpy at the compression stage inlet; and $\eta$ is the compressor stage isentropic efficiency. In the literature, compressor stage isentropic efficiencies in the range $80 \%$ to $90 \%$ have been used $[2,6,8,12,15,16]$. In this study $\eta$ is fixed at $85 \%$.

Stage enthalpy and entropy values, Hout $S_{i}=f\left(S_{i}\right.$, Pout $\left._{i}, x_{i}\right), \operatorname{Hin}_{i}=f\left(\right.$ To, Pin $\left._{i}, x_{i}\right)$, and $S_{i}=$ $f\left(\operatorname{Pin}_{i}\right.$, To $\left._{0}\right)$ were calculated using the TREND properties package, where $S_{i}$ is the entropy at the inlet to stage $i$ and $x_{i}$ is the composition at the inlet to stage $i$. In the oxyfuel study cases the $\mathrm{CO}_{2}$ stream is dry and $x_{i}$ is therefore fixed. In the other cases, the $\mathrm{CO}_{2}$ stream is saturated with water below 30 bar(a) and, therefore, the water content and $x_{i}$ varies with temperature and pressure. In these cases, $x_{i}=f\left(T_{o}\right.$, Pin $\left._{i}\right)$ was also calculated using TREND.

When a liquid phase is possible at To, the final stage inlet pressure, $\operatorname{Pin}_{n}$, is fixed 5 bar above the mixture dewpoint pressure, $P_{D P}$; when it is not, $\operatorname{Pin}_{n}$ is fixed 5 bar above the crycondenbar pressure for 
the $\mathrm{CO}_{2}$ mixture, $P_{C R}$. The final stage of the compressor represents a pump when the $\mathrm{CO}_{2}$ stream is in the liquid phase.

A summary of the main compressor modelling parameters is provided below in Table 1.

Table 1. Summary of compressor modelling parameters.

\begin{tabular}{ccc}
\hline Parameter & Constrained Cases & Unconstrained Cases \\
\hline Pressure Ratio, $P r$ & $<2$ & $<10$ \\
Efficiency, $\eta$ & & $85 \%$ \\
Stage pressure drop, $\Delta P$ & $0.5 \mathrm{bar}$ \\
Final stage inlet pressure, $P i n_{n}$ & Minimum of $P_{D P}+5 \mathrm{bar}$ and,$P_{C R}+5 \mathrm{bar}$ \\
\hline
\end{tabular}

\subsection{Study Parameters}

Three $\mathrm{CO}_{2}$ capture scenarios were modeled: Pre-combustion capture, post-combustion capture, and oxyfuel. In all of the three scenarios the compressor discharge pressure, $P n$, is studied in the range 90 bar(a) to 180 bar(a). Each compressor aftercooler has an outlet temperature, To, which is studied in the range $288 \mathrm{~K}$ to $323 \mathrm{~K}$. The scenario specific parameters for each of the three capture cases are described below and summarized at the end of this section in Table 2.

\subsubsection{Post-Combustion Capture}

A typical post-combustion capture processes is represented by an amine based solvent absorption unit. This type of process produces a relatively pure stream of $\mathrm{CO}_{2}$ at atmospheric pressure that is saturated with water. Typically, $\mathrm{CO}_{2}$ streams that are to be transported in a pipeline are dried part-way through the compression process to take advantage of water drop-out in the early stages of compression [2]. In this study the break point for dehydration was taken as 30 bar(a): All stages below 30 bar(a) were modeled with a feed stream that was saturated with water; all above were modeled as dry. The dry stream composition used in this study, $99.99 \mathrm{~mole} \% \mathrm{CO}_{2}$ and $0.01 \mathrm{~mole} \%$ nitrogen, was based on an assessment of data published by DNV [17] and the TRENDS project [18].

\subsubsection{Pre-Combustion Capture}

There are a wide variety of competing pre-combustion capture processes [19]. Based on a review of $[20,21]$ the basis for this study is a stream of $\mathrm{CO}_{2}$ originating from steam-methane reformer that is captured using an MDEA solvent. As in the post combustion cases, the feed stream will be at atmospheric pressure and saturated with water below 30 bar(a). The dry composition, 99.5 mole $\% \mathrm{CO}_{2}$ and $0.5 \mathrm{~mole} \%$ methane, was, again, based on an assessment of data published by DNV [17] and the TRENDS project [18].

\subsubsection{Oxyfuel Capture}

Within a normal oxyfuel flue gas purification process the operating pressure for the initial stages of the $\mathrm{CO}_{2}$ compressor are set to optimize the performance of the purification process. This type of optimization falls outside of the scope of this study and, therefore, the feed pressure for the $\mathrm{CO}_{2}$ compression process studied here is taken as the highest product stream pressure resulting from the oxyfuel purification process, i.e., de-coupled from the optimization of the purification process. The $\mathrm{CO}_{2}$ stream from the purification process is dry, the main impurities being $\mathrm{N}_{2}, \mathrm{O}_{2}$, and argon [17]. The level of these impurities is not limited by technical barriers [9] and technologies for high and low purity has been investigated $[8,15]$. In this study, the highest pressure of the $\mathrm{CO}_{2}$ feed stream leaving the purification unit is taken as $16.5 \mathrm{bar}(\mathrm{a})$ and its composition $96.16 \mathrm{~mole} \% \mathrm{CO}_{2}, 2.45 \mathrm{~mole} \%$ nitrogen, $0.96 \mathrm{~mole} \%$ argon, and 0.43 mole\% oxygen based on Posch et al. [8]. 
Table 2. Summary of compressor modeling parameters.

\begin{tabular}{cccc}
\hline Parameter & Post & Pre & Oxyfuel \\
\hline Cooling temperature, To & $288 \mathrm{~K}$ to $323 \mathrm{~K}$ & $288 \mathrm{~K}$ to $323 \mathrm{~K}$ & $288 \mathrm{~K}$ to $323 \mathrm{~K}$ \\
Discharge pressure, $P n$ & 90 bar(a) to 180 bar(a) & 90 bar(a) to 180 bar(a) & 90 bar(a) to 180 bar(a) \\
Inlet pressure, Pin 1 & 1.01 bar(a) & 1.01 bar(a) & 16.5 bar(a) \\
& & & $\mathrm{CO}_{2} 96.16$ mole $\%$ \\
Dry stream composition & $\mathrm{CO}_{2} 99.99$ mole $\%$ & $\mathrm{CO}_{2} 99.5$ mole $\%$ & $\mathrm{~N}_{2} 2.45$ mole $\%$ \\
& $\mathrm{~N}_{2} 0.01$ mole $\%$ & $\mathrm{CH}_{4} 0.5$ mole $\%$ & $\mathrm{Ar} 0.96$ mole $\%$ \\
& & & $\mathrm{O}_{2} 0.43$ mole $\%$ \\
\hline
\end{tabular}

\subsection{Optimization of Compressor Energy Consumption}

Optimization of the compressor stage pressure ratios, $P r_{n}$, was carried in MATLAB using the functions GA, Fmincon, and Fminsearch. Fminsearch uses a simplex algorithm that is suitable for unconstrained, multi-variable, non-linear optimization problems. A benefit of this method is that it will usually quickly converge to a solution, a downside is that in some cases a local minimum may be obtained. Fmincon is a gradient-based method that is designed to work on problems where the objective and constraint functions are both continuous and have continuous first derivatives. GA can solve smooth or non-smooth optimization problems with or without constraints. It is a stochastic, population-based algorithm. GA is generally slower to reach a solution than Fminsearch and Fmincon, but it is more reliable in solving for the global minimum. All of these algorithms were used with MATLAB default options unless stated below.

\subsubsection{Variables, Initial Guesses, and Constraints}

Since the final stage inlet pressure, $\operatorname{Pin}_{n}$, is fixed in the compressor model, the final stage pressure ratio, $P r_{n}$, is not a variable in the optimization problem. In addition, since the penultimate stage pressure ratio, $P r_{n-1}$, is calculated from the product of the other pressure ratios and $P i n_{n}, P r_{n-1}$ is not a variable in the optimisation problem either. The result is that for an $n$ stage compressor, $n-2$ pressure ratios are variables.

The initial guesses for the stage pressure ratios were generated by assuming that all the stage pressure ratios were equal. The subsequent initial guesses used by the optimization algorithms were selected from previous optimization runs when available. The Fminsearch and Fmincon algorithms were generally used to improve initial guesses before GA was used.

In constrained cases, bound constraints are specified for all the variable pressure ratios such that $P r_{i}<2$. In both the constrained and unconstrained cases, a minimum pressure ratio bound constraint $\operatorname{Pr}_{i}>1.2$ was also used to avoid problematic optimization solutions, e.g., where Pout ${ }_{i}-\Delta P<\operatorname{Pin}_{i}$.

\subsubsection{Objective Function}

Since the pressure ratio for the next to last compression stage, $P r_{n-1}$, was calculated within the compressor model and was not a variable in the optimization problem, an additional constraint was applied in the form of a penalty function, $P_{1}$, to ensure that $P r_{n-1}>1.2$ for all cases, and $P r_{n-1}<2$ in the constrained cases. The form of the penalty function was:

$$
\text { if } 1.2<P r_{n-1}<2, P_{1}=0 \text {, else } P_{1}=100 \cdot\left(P r_{n-1}-1.5\right)^{2} .
$$

An additional penalty function, $P_{2}$, was included to avoid two-phase conditions at any stage inlet conditions. This second penalty function had the form:

$$
\text { if } T o-T_{D P}>5, P_{2}=0, \text { else } P_{2}=\sum_{i=1}^{n}\left[0.01+\left(5-T o-T_{D P}\right)^{2}\right],
$$

where $T_{D P}=f\left(P_{i}, x_{i}\right)$ is the dewpoint temperature of the gas mixture, $x$, at stage $i$. 
The objective of the optimization problem was to minimize an objective function, $X$, which included contributions from the two penalty functions:

$$
X=W_{c}+P_{1}+P_{2} .
$$

\subsection{Identifying the Optimum Number of Compression Stages}

Although the overall optimum number of compression stages is the one that corresponds with the minimum energy consumption, the percentage gain per additional compression stage is also important because of the additional costs implied. To acknowledge this, the overall optimum number of stages is defined in this study as the number of stages above which the percentage decrease in energy consumption falls below $2 \%$. This is an arbitrary breakpoint based on a review of the optimization data.

\section{Results and Discussion}

The main results of the optimization work are presented below. In addition, links to the full set of data generated by this study are presented towards the end of this article under the heading Supplementary Materials.

\subsection{The Benefits of Optimization}

The amount of energy that is saved through the optimization of stage pressure ratios will vary from cases to case. Figure 3 illustrates that the gain could be as much as $10 \%$ of the total compression energy consumption, although in some cases it was much less.

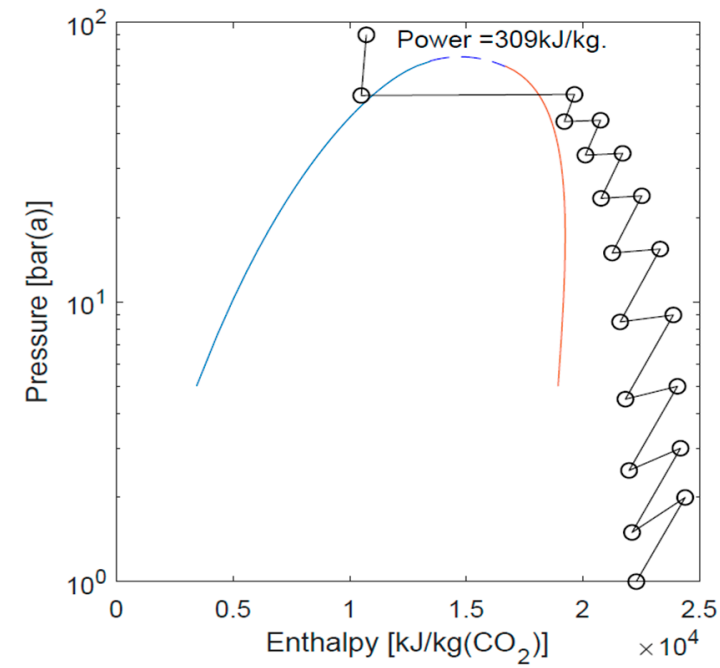

(a)

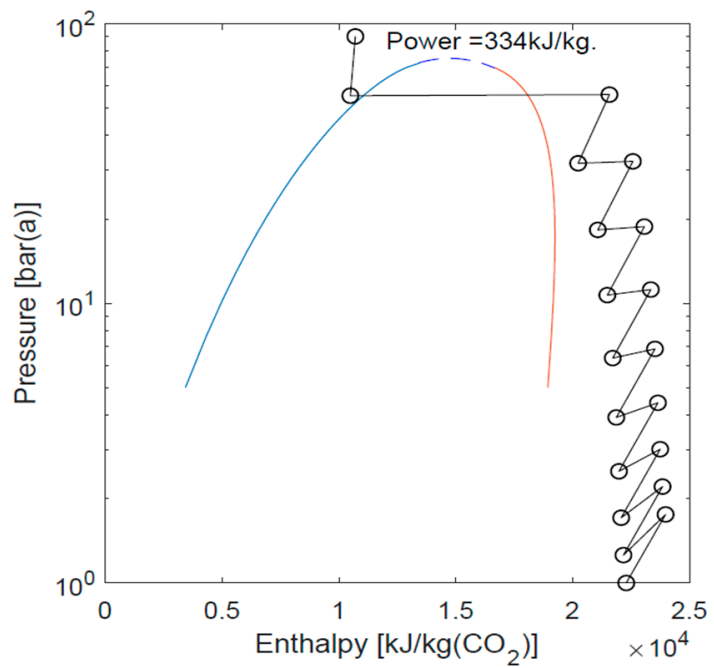

(b)

Figure 3. Energy consumption for a 10 stage $\mathrm{CO}_{2}$ compressor, post-combustion capture case, $P_{n}=90$ bar(a) and To $=288 \mathrm{~K}$ with (a) constant $P r$ and (b) optimized $\operatorname{Pr}$.

\subsection{Consistency Checking and Optimum Stages}

In Figure 4, the relative compression energy consumption vs. number of compression stages is plotted for all of the results from the post-combustion capture cases (grey crosses). Seven sets of data are highlighted to help illustrate trends. Data for the pre-combustion capture cases and the oxyfuel cases are presented in Figures 5 and 6, respectively. 


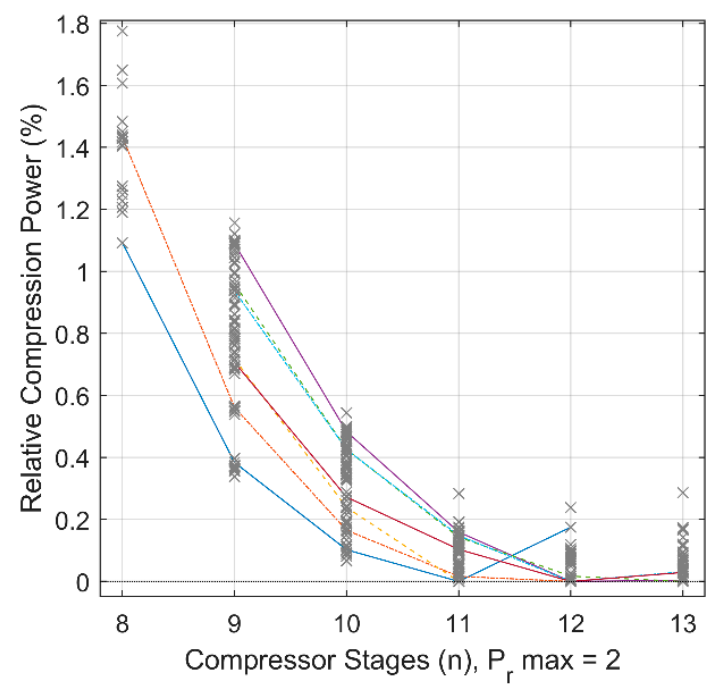

(a)

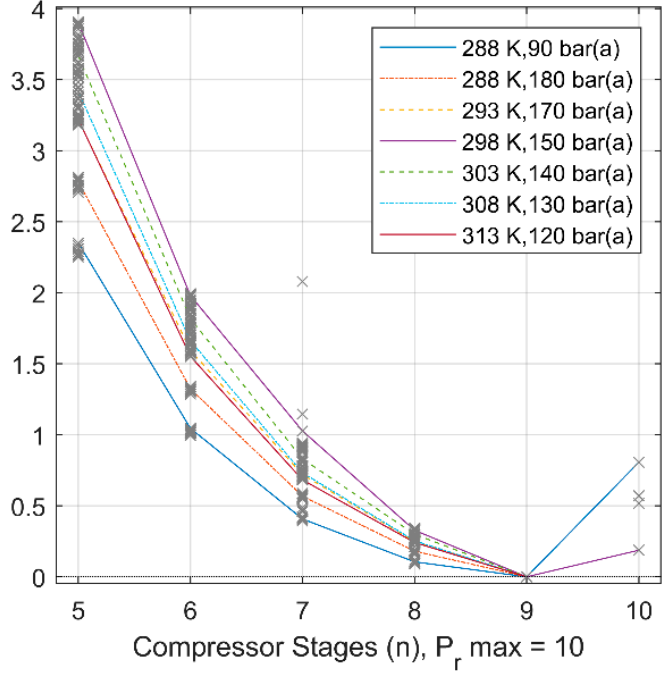

(b)

Figure 4. Relative energy consumption vs. stages for post-combustion capture, (a) constrained cases and (b) unconstrained cases (right).

Figures 4-6 show that the energy consumption of the compression process often varied by less than $1 \%$ for compressor designs either side of the optimum number of stages, because of this, the optimization must be of high quality to accurately identify the optimum number of stages.

In many cases the fminsearch and fmincon algorithms did not give the required level of accuracy to show these trends and all the data presented here was generated by the GA algorithm, albeit, in many cases, from guesses provided by the other algorithms.

Although the trends visible in Figures 4-6 show a couple of examples of counter-intuitive behavior, overall they illustrated good consistency in the results of the study, indicating consistent and reliable level of optimization.

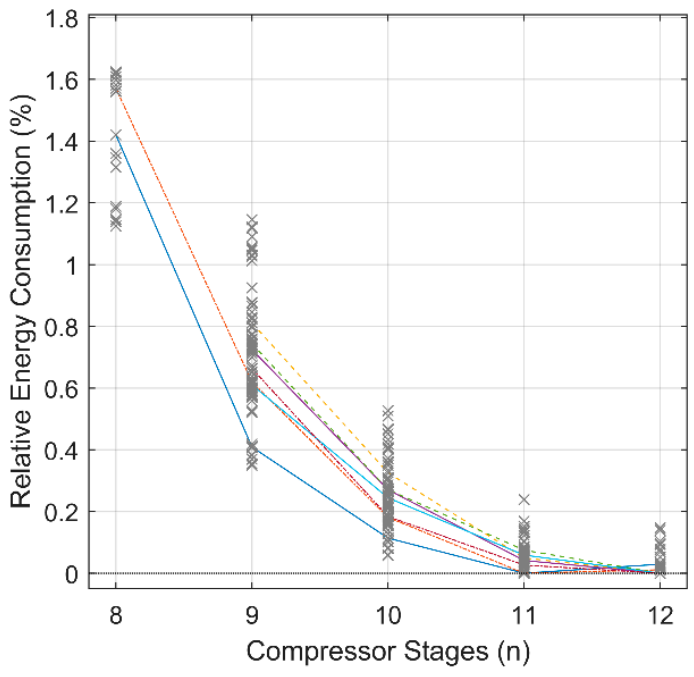

(a)

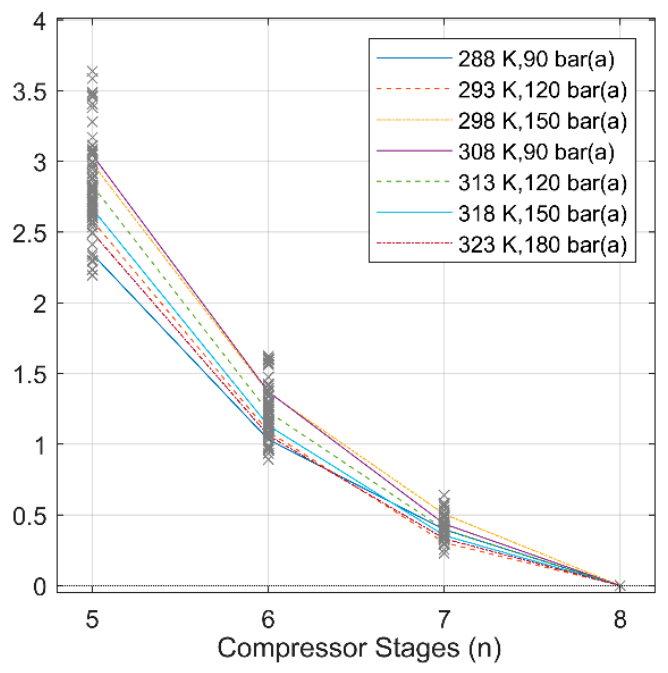

(b)

Figure 5. Relative energy consumption vs. stages for pre-combustion capture, (a) constrained cases and (b) unconstrained cases. 


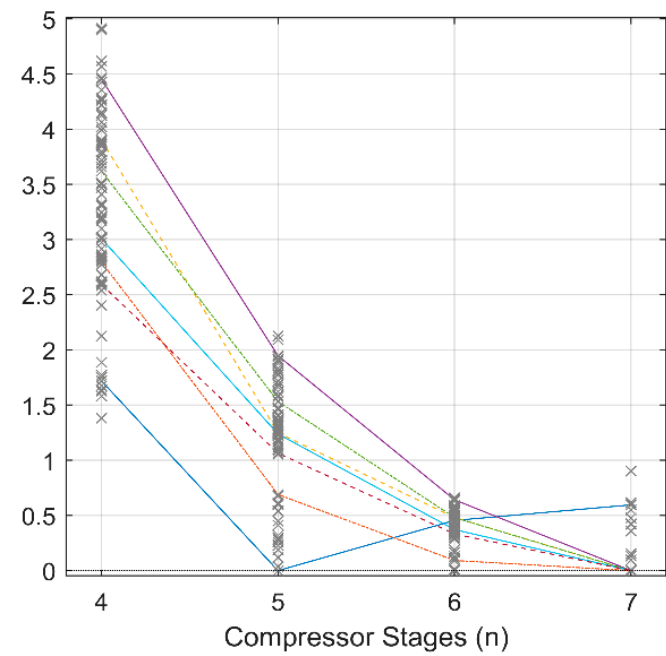

(a)

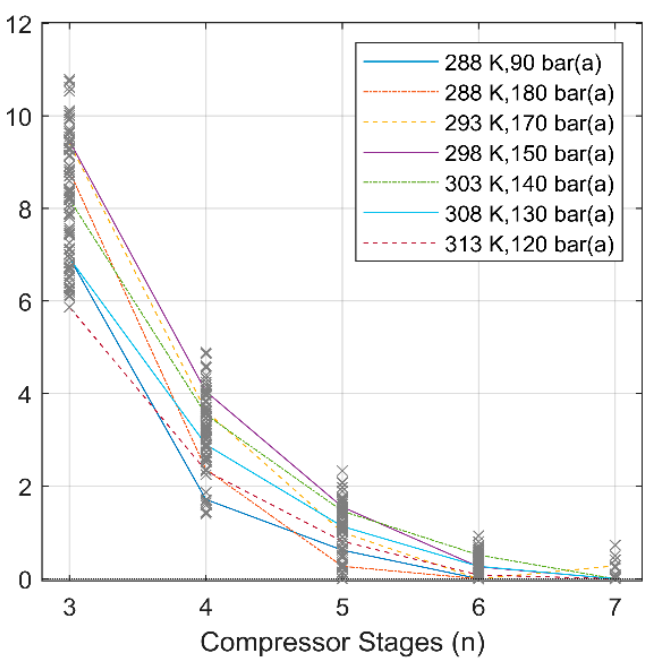

(b)

Figure 6. Relative energy consumption vs. compressor stage, oxyfuel cases, (a) constrained cases and (b) unconstrained cases.

\subsection{Variation of Energy Consumption with Cooling Temperature and Pressure}

Figures 7-9 show how compression energy consumption varied with cooling temperature and compressor discharge pressure for the three $\mathrm{CO}_{2}$ capture scenarios. The optimum number of compression stages was overlaid.

The results show that optimum energy consumption was more strongly dependent on the cooling temperature than discharge pressure. This reflects the fact that the energy consumption for the final, pumped, stage was lower than the other compressor stages. The results also show that there was little difference between the energy consumption for the post and pre-combustion cases, which was because the composition of these two streams was very similar.

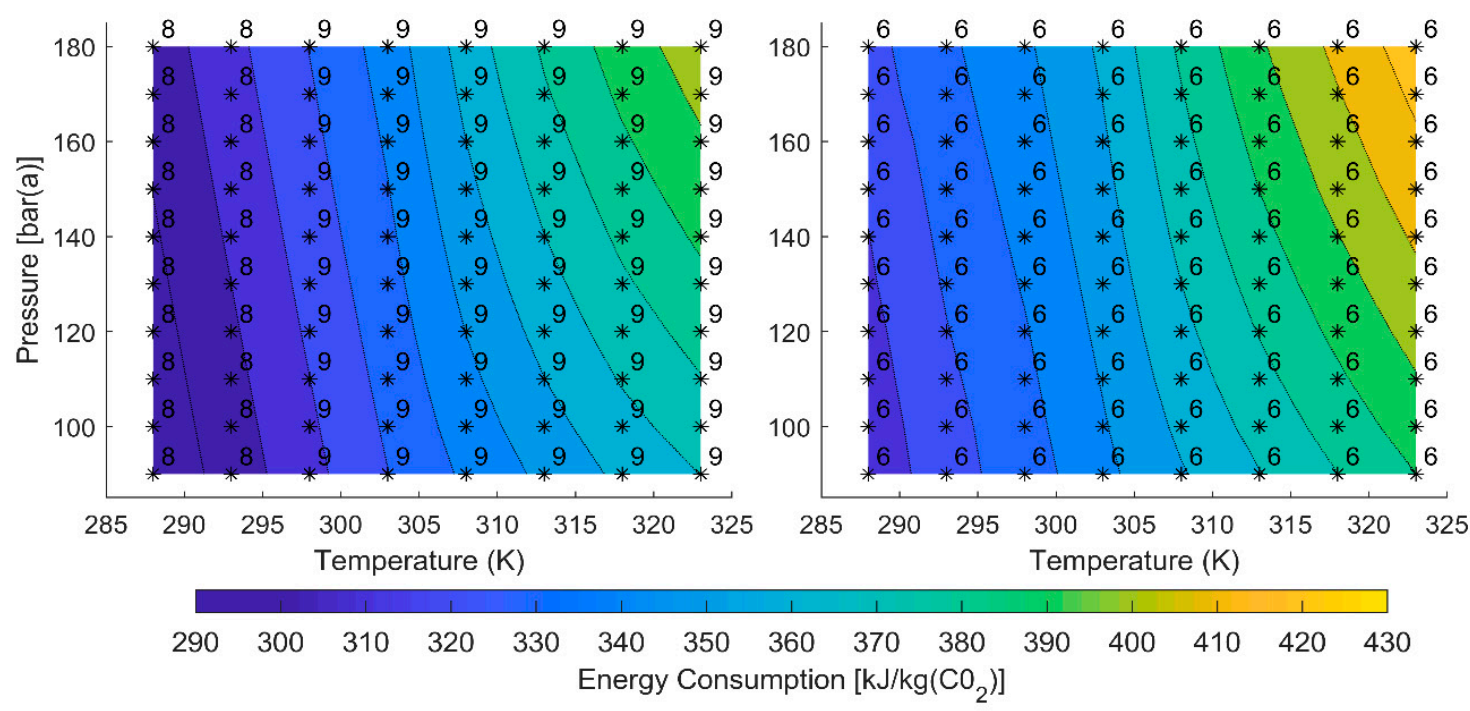

(a)

(b)

Figure 7. Post-combustion capture cases, optimized compression energy consumption and number of stages, (a) constrained cases and (b) unconstrained cases. 


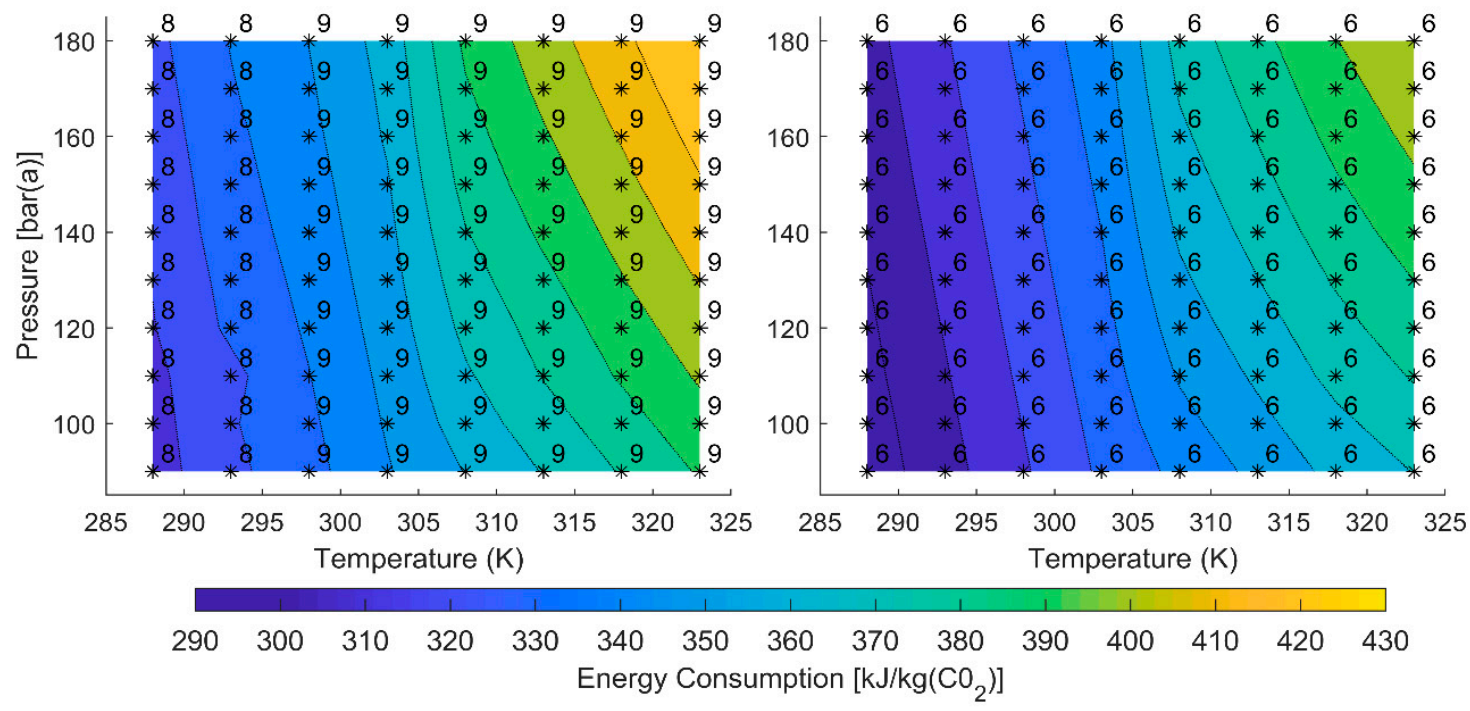

(a)

(b)

Figure 8. Pre-combustion capture cases, optimized compression energy consumption and number of stages, (a) constrained cases and (b) unconstrained cases.

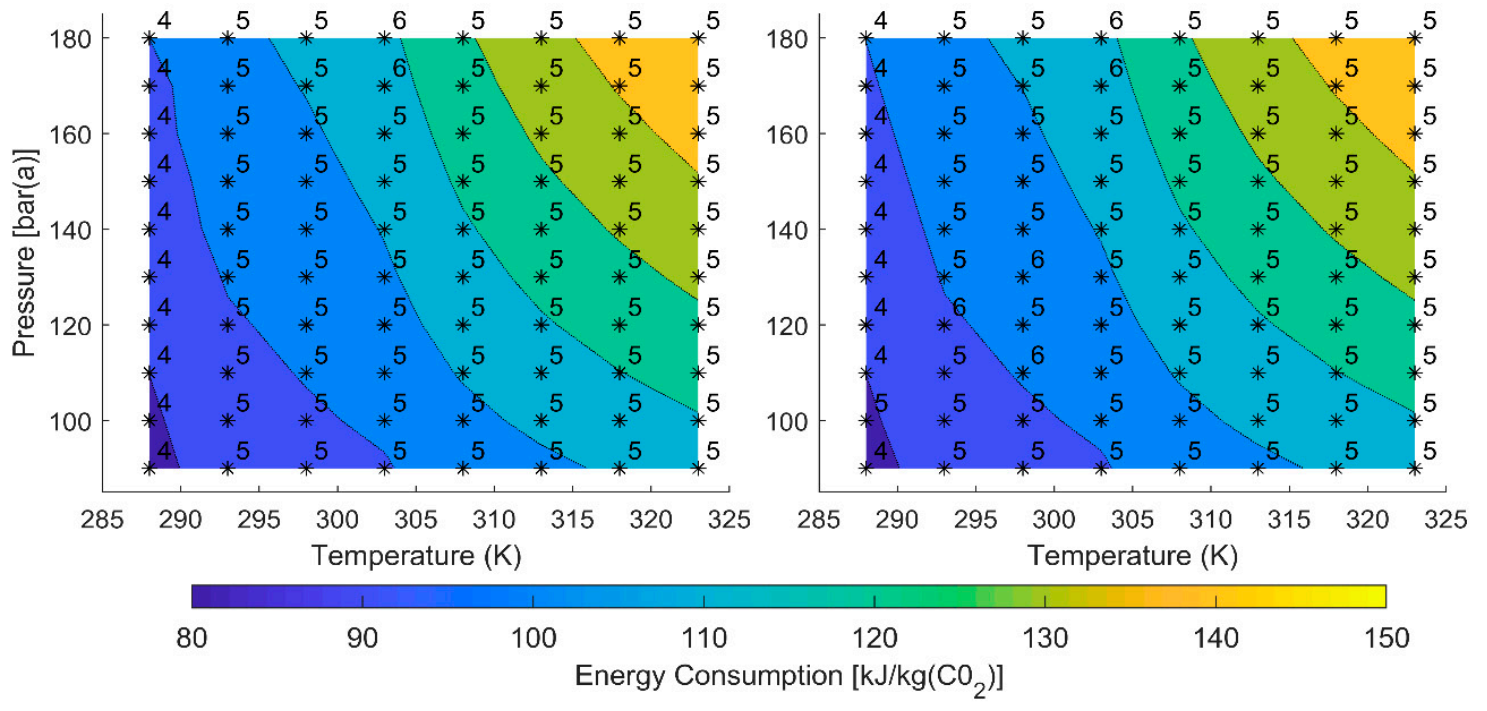

(a)

(b)

Figure 9. Oxyfuel cases, optimized compression energy consumption and number of stages, (a) constrained cases and (b) unconstrained cases.

\subsection{Constrained vs. Unconstrained Cases}

Figure 10 presents results for the percentage reduction in energy consumption for the unconstrained cases relative to the constrained cases, Figure 10a shows this for post-combustion cases and 10b for pre-combustion cases. The corresponding reduction in the number of compression stages required was overlaid. The oxyfuel cases were not shown here because the percentage reduction was close to zero in all cases.

The results in Figure 10 show that in all cases considered the unconstrained cases (those representing a design with multiple impellers per stage) had an optimum number of stages that was 2 to 3 fewer than the constrained cases (those assuming one impeller per stage). This represents a potentially significant saving in compressor cost. In addition, the unconstrained cases offered an average $6 \%$ saving in the energy required for compression. 


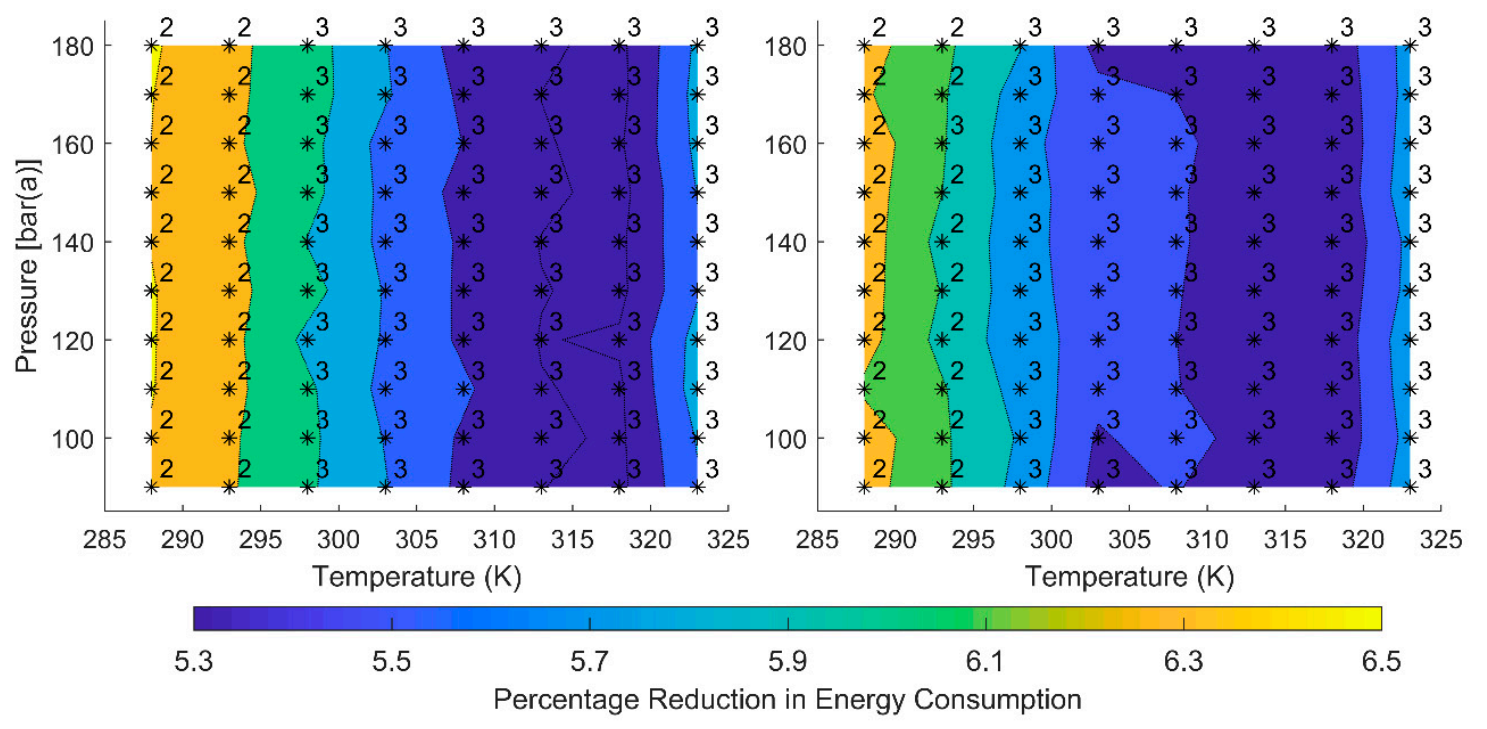

(a)

(b)

Figure 10. Reduction in energy consumption (\%) for the unconstrained cases relative to the constrained cases with reduction in the number of compression stages overlaid, (a) post-combustion cases, (b) pre-combustion cases.

\section{Discussion}

Table 3 summarizes the results from Figures 7-9 for all constrained (const.) and unconstrained (u.const.) cases. In Table 3 we see that the energy consumption for the post combustion $\mathrm{CO}_{2}$ compression cases varies in the range $292 \mathrm{~kJ} / \mathrm{kg} \mathrm{CO}_{2}$ to $425 \mathrm{~kJ} / \mathrm{kg} \mathrm{CO}_{2}$. This compares well with the range of $80-120 \mathrm{kWh}_{\mathrm{e}} / \mathrm{tCO}_{2}$ (equal to $288-432 \mathrm{~kJ} / \mathrm{kgCO}_{2}$ ) reported by Jordal et al. [2].

Table 3. Summary of the range of optimized energy consumption and number of stages.

\begin{tabular}{ccccccc}
\hline Parameter & $\begin{array}{c}\text { Post } \\
\text { const. }\end{array}$ & $\begin{array}{c}\text { Post } \\
\text { u.con. }\end{array}$ & $\begin{array}{c}\text { Pre } \\
\text { const. }\end{array}$ & $\begin{array}{c}\text { Pre } \\
\text { u.con. }\end{array}$ & $\begin{array}{c}\text { Oxy } \\
\text { const. }\end{array}$ & $\begin{array}{c}\text { Oxy } \\
\text { u.con. }\end{array}$ \\
\hline Energy, $W_{c}\left[\mathrm{~kJ} / \mathrm{kg}\left(\mathrm{CO}_{2}\right)\right]$ & 292 to 406 & 312 to 425 & 316 to 431 & 294 to 140 & 87 to 150 & 87 to 150 \\
Stages, $n(-)$ & 8 to 9 & 6 & 8 to 9 & 6 & 4 to 5 & 4 to 6 \\
\hline
\end{tabular}

Comparing some more specific cases from the literature, we see that for a post combustion case with 110 bar(a) discharge and $30^{\circ} \mathrm{C}$ cooling, Amorllahi et al. [18] reported an energy consumption of $330 \mathrm{~kJ} / \mathrm{kg}$, which is practically identical to the value found in this study as presented in Figure $7 \mathrm{a}$. Alhajaj et al. [22] reported the energy consumption for a 5 stage $\mathrm{CO}_{2}$ compressor with a $14 \mathrm{MPa}$ discharge pressure and $50{ }^{\circ} \mathrm{C}$ cooling (representing warm climates) to be $104.6 \mathrm{kWh}$ per ton of $\mathrm{CO}_{2}$ $\left(=380 \mathrm{~kJ} / \mathrm{kg}\right.$ of $\left.\mathrm{CO}_{2}\right)$, which compares well with $390 \mathrm{~kJ} / \mathrm{kg}$ of $\mathrm{CO}_{2}$ found in this study, Figure $7 \mathrm{a}$. Alhajaj et al. [22] also reported an energy consumption of $82.4 \mathrm{kWh} / \mathrm{ton}$ of $\mathrm{CO}_{2}\left(=297 \mathrm{~kJ} / \mathrm{kg}\right.$ of $\left.\mathrm{CO}_{2}\right)$ for the same compressor with a $20^{\circ} \mathrm{C}$ cooling temperature (representing colder climates), which also compares well with $311 \mathrm{~kJ} / \mathrm{kg}$ of $\mathrm{CO}_{2}$ found in this study from Figure $7 \mathrm{a}$.

For the constrained post and pre-combustion cases the practical minimum number of stages varies between eight and nine depending on To. When To $\leq 293 \mathrm{~K}$ it is possible to reach a pressure where the $\mathrm{CO}_{2}$ stream will condense in seven stages and, hence, the overall minimum stages is eight. When To $>293 \mathrm{~K}$, nine stages are required. Since the energy consumption for the eight and nine stage cases also falls within $2 \%$ of the overall minimum, as illustrated in Figures $4 \mathrm{a}$ and $5 \mathrm{a}$, they also satisfy the criteria for the optimum number of compression stages used in this study. This means that the optimum number of stages presented in Figures $7 \mathrm{a}$ and $8 \mathrm{a}$ is dictated by the practical minimum number of stages for these cases. 
For the unconstrained post and pre-combustion cases, Figures $4 \mathrm{~b}$ and $5 \mathrm{~b}$ show that the six stage cases all fall just within the $2 \%$ limit and therefore represent the optimum number of stages for this study presented in Figures $7 \mathrm{~b}$ and $8 \mathrm{~b}$.

For the oxyfuel cases, the picture is less clear and Figure 6 shows that either four or five stages represent the optimum based on the definition used here. Figure 8 also shows the quality of the optimization is slightly less consistent for these cases, which is reflected in Figure 9. Figure 9 also shows that there is very little difference between the energy consumption for the constrained and unconstrained cases. This reflects the lost benefit that the use of pressure ratios greater than 2 provides to the unconstrained pre and post-combustion cases in the early stages of the compression process.

\section{Conclusions}

The comparison of the results from this study with other published data indicates that the energy consumptions predicted are reliable and can support the development of a system model capable of comparing energy consumption of a wide variety of CCS scenarios, which was the aim of this work.

In all cases studied here, the cooling temperature has a more substantial impact on optimum energy consumption than the compressor discharge pressure, because of this, it is concluded that the comparison of different CCS schemes and operating scenarios should consider the important role ambient temperature plays in determining the energy consumption.

This study also found that compressor designs with multiple impellers per stage have an advantage in terms of energy consumption and the optimum number of stages required compared to designs where one impeller per stage is used. Because of this, the performance maps for the unconstrained cases presented in Figure 7b, Figure 8b, and Figure $9 \mathrm{~b}$ should be used as the basis for further study work.

\section{Nomenclature}

$\begin{array}{ll}\text { Hin }_{i} & \text { Enthalpy at the inlet to stage } i \\ \text { Hout } S_{i} & \text { Enthalpy at the outlet if stage } i \text { (isentropic basis) } \\ \mathrm{n} & \text { Number of compressor stages } \\ P_{C R} & \text { Crycondenbar pressure } \\ P_{D P} & \text { Dew point pressure } \\ \text { Pin }_{i} & \text { Inlet pressure pressure for stage } i \\ \text { Pout }_{i} & \text { Outlet pressure pressure for stage } i \\ \text { rr }_{i} & \text { Pressure ratio for stage } i \\ \Delta \mathrm{P} & \text { Aftercooler pressure drop } \\ S_{i} & \text { Entropy for stage } i \\ \mathrm{To}_{\mathrm{C}} & \text { Aftercooler outlet temperature } \\ \mathrm{W}_{\mathrm{c}} & \text { Energy used in compression } \\ x_{i} & \text { Gas composition stage } i \\ \eta & \text { Isentropic efficiency }\end{array}$

Supplementary Materials: The following are available online at http:/www.mdpi.com/1996-1073/12/9/1603/s1, Figure S1: Post-combustion capture cases, compression energy consumption with fixed (un-optimized) stage pressure ratios, (a) constrained cases and (b) unconstrained cases. Figure S2: Pre-combustion capture cases, compression energy consumption with fixed (un-optimized) stage pressure ratios, (a) constrained cases and (b) unconstrained cases. Figure S3: Oxy-combustion capture cases, compression energy consumption with fixed (un-optimized) stage pressure ratios, (a) constrained cases and (b) unconstrained cases. All data from Figures 7-9 and Figures S1-S3 in CSV .txt format.

Author Contributions: Conceptualization, S.J.; methodology, S.J.; formal analysis, S.J.; writing-original draft preparation, S.J.; writing-review and editing, E.B.; supervision, E.B.

Funding: This research received no external funding. The APC was funded by a grant from the publication fund of UiT The Arctic University of Norway.

Conflicts of Interest: The authors declare no conflict of interest. 


\section{References}

1. Lucquiaud, M.; Liang, X.; Errey, O.; Chalmers, H.; Gibbins, J. Addressing technology uncertainties in power plants with post-combustion capture. Energy Procedia 2013, 37, 2359-2368. [CrossRef]

2. Jordal, K.; Aspelund, A. Gas conditioning-The interface between $\mathrm{CO}_{2}$ capture and transport. Int. J. Greenh. Gas Control. 2007, 1, 343-354.

3. Dittmer, R.; Strube, R. Integrally-geared compressors as state-of-the-art technology. Carbon Capture J. 2015, $47,15-18$.

4. Habel, R.; Wacker, C. Innovative and proven $\mathrm{CO}_{2}$ compression technology for CCS and EOR. Carbon Capture J. 2009, 11, 15-18.

5. Irlam, L. Global Costs of Carbon Capture and Storage, 2017 Update; Global CCS Institute: Docklands, Australia, 2017.

6. Romeo, L.M.; Bolea, I.; Lara, Y.; Escosa, J.M. Optimization of intercooling compression in $\mathrm{CO}_{2}$ capture systems. Appl. Therm. Eng. 2009, 29, 1744-1751. [CrossRef]

7. Luo, X.; Wang, M.; Chen, J. Heat integration of natural gas combined cycle power plant integrated with post-combustion $\mathrm{CO}_{2}$ capture and compression. Fuel 2015, 151, 110-117. [CrossRef]

8. Posch, S.; Haider, M. Optimization of $\mathrm{CO}_{2}$ compression and purification units $\left(\mathrm{CO}_{2} \mathrm{CPU}\right)$ for CCS power plants. Fuel 2012, 101, 254-263. [CrossRef]

9. Font-Palma, C.; Errey, O.; Corden, C.; Chalmers, H.; Lucquiaud, M.; Sanchez Del Rio, M.; Jackson, S.; Medcalf, D.; Livesey, B.; Gibbins, J.; et al. Integrated oxyfuel power plant with improved $\mathrm{CO}_{2}$ separation and compression technology for EOR application. Process. Saf. Environ. Prot. 2016, 103, 455-465. [CrossRef]

10. Alabdulkarem, A.; Hwang, Y.; Radermacher, R. Development of $\mathrm{CO}_{2}$ liquefaction cycles for $\mathrm{CO}_{2}$ sequestration. Appl. Therm. Eng. 2012, 33, 144-156. [CrossRef]

11. Harkina, T.; Hoadley, A.; Hooper, B. A comparison of the Process Integration of Shockwave $\mathrm{CO}_{2}$ compression with conventional turbo machinery into PCC power station design. Energy Procedia 2011, 4, 1339-1346. [CrossRef]

12. Pei, P.; Barse, K.; Gil, A.J.; Nasah, J. Waste heat recovery in $\mathrm{CO}_{2}$ compression. Int. J. Greenh. Gas Control. 2014, 30, 86-96. [CrossRef]

13. Calado, M. Modeling and design synthesis of a CCS compression train system via MINLP optimization. Instituto Superior Técnico, Universidade de Lisboa. 2012. Available online: https:/fenix.tecnico. ulisboa.pt/downloadFile/395144614662/ExtendedAbstract_MarioCalado_12Outubro2012.pdf (accessed on 26 April 2019).

14. Jackson, S.; Brodal, E. A comparison of the energy consumption for $\mathrm{CO}_{2}$ compression process alternatives. Available online: https://iopscience.iop.org/article/10.1088/1755-1315/167/1/012031/pdf (accessed on 26 April 2019).

15. Pipitone, G.; Bolland, O. Power generation with $\mathrm{CO}_{2}$ capture: Technology for $\mathrm{CO}_{2}$ purification. Int. J. Greenh . Gas Control. 2009, 3, 528-534. [CrossRef]

16. Amrollahi, Z.; Ystad, P.A.M.; Ertesvåg, I.S.; Bolland, O. Optimized process configurations of post-combustion $\mathrm{CO}_{2}$ capture for natural-gas-fired power plant-Power plant efficiency analysis. Int. J. Greenh. Gas Control. 2012, 8, 1-11. [CrossRef]

17. D.N.V. Recommended Practice, DNV-RP-J202, Design and Operation of $\mathrm{CO}_{2}$ Pipelines. DNV, 2010. Available online: https://rules.dnvgl.com/docs/pdf/DNV/codes/docs/2010-04/RP-J202.pdf (accessed on 26 April 2019).

18. Eickhoff, C.; Neele, F.; Hammer, M.; DiBiagio, M.; Hofstee, C.; Koenen, M.; Fischer, S.; Isaenko, A.; Brown, A.; Kovacs, T. IMPACTS: Economic Trade-offs for $\mathrm{CO}_{2}$ Impurity Specification. Energy Procedia 2014, 63, 7379-7388. [CrossRef]

19. Damen, K.; Troost, M.v.; Faaij, A.; Turkenburg, W. A comparison of electricity and hydrogen production systems with $\mathrm{CO}_{2}$ capture and storage. Part A: Review and selection of promising conversion and capture technologies. Prog. Energy Combust. Sci. 2006, 32, 215-246. [CrossRef]

20. IEA Greenhouse Gas R\&D Programme. Techno-Economic Evaluation of SMR Based Standalone (Merchant) Hydrogen Plant with CCS. 2017. Available online: https://ieaghg.org/exco_docs/2017-02.pdf (accessed on 26 April 2019). 
21. Tanaka, Y.; Sawada, Y.; Tanase, D.; Tanaka, J.; Shiomi, S.; Kasukawa, T. Tomakomai CCS Demonstration Project of Japan, $\mathrm{CO}_{2}$ Injection in Process. Energy Procedia 2017, 114, 5836-5846. [CrossRef]

22. Alhajaj, A.; Mac Dowell, N.; Shah, N. A techno-economic analysis of post-combustion $\mathrm{CO}_{2}$ capture and compression applied to a combined cycle gas turbine: Part I. A parametric study of the key technical performance indicators. Int. J. Greenh. Gas Control. 2016, 44, 26-41. [CrossRef]

(C) 2019 by the authors. Licensee MDPI, Basel, Switzerland. This article is an open access article distributed under the terms and conditions of the Creative Commons Attribution (CC BY) license (http://creativecommons.org/licenses/by/4.0/). 